\title{
Quantitative MDCT and MRI assessment of hepatic steatosis in genotype 4 chronic hepatitis $C$ patients with fibrosis
}

Gehan S. Seifeldein ${ }^{1}$, Elham A. Hassan², Hala M. Imam³ ${ }^{3}$ Rania Makboul ${ }^{4}$, Naglaa K. Idriss ${ }^{5}$, Marwa A. Gaber ${ }^{5}$ and Reem M. Elkady ${ }^{1,6^{*}}$ (D)

\begin{abstract}
Background: Hepatic steatosis has been shown to worsen the course of liver disease in chronic hepatitis C (CHC) patients, and it may reduce the efficacy of antiviral therapy and accelerate disease progression. In this cross-sectional study, we aimed to evaluate the role of multidetector computed tomography and magnetic resonance imaging (MRI) in the quantitative assessment and grading of hepatic steatosis to evaluate the association between hepatic steatosis and fibrosis in Egyptian genotype 4-CHC (G4-CHC) patients.
\end{abstract}

Results: Histopathological hepatic steatosis was found in $70.3 \%$ of 155 patients. No correlation was found between the $\mathrm{CT}$ ratio and pathological hepatic steatosis. Proton density fat fraction, T1-fat fraction, and fat percentage correlated with histological steatosis grading $(r=0.953, p<0.001 ; r=0.380, p=0.027$ and $r=0.384, p=0.025$, respectively). An agreement between steatosis grading by histology and $1 \mathrm{H}$-MRS was found in $74.2 \%$ of patients. Compared to other MRI modalities, proton density fat fraction had the highest area under the receiver operating characteristic curve (AUC), with $0.910,0.931$, and 0.975 for mild, moderate, and severe steatosis, respectively. The cutoff with the best ability to predict steatosis was $>4.95$ for a proton density fat fraction (AUC $=0.958$ ) with $95.8 \%$ sensitivity, $90 \%$ specificity, $78.5 \%$ positive predictive value, and $96.1 \%$ negative predictive value.

Conclusion: $1 \mathrm{H}-\mathrm{MRS}$ had good diagnostic performance in predicting hepatic steatosis in G4-CHC patients, and hence, it may offer a useful noninvasive quantitative modality for grading steatosis with clinical applicability, especially in those where a liver biopsy cannot be done.

Keywords: Liver, Steatosis, MDCT, 1H-MRS, Fibrosis, Biopsy

\section{Background}

Intracellular fat accumulation (steatosis) is a common feature in different liver diseases [1]. Steatosis is the histological hallmark of non-alcoholic fatty liver disease (NAFLD) but also may occur with alcohol abuse, viral hepatitis, HIV and genetic lipodystrophies, and chemotherapy [2]. Studies have shown that $5-15 \%$ of patients with NAFLD present with established cirrhosis on liver

\footnotetext{
${ }^{*}$ Correspondence: reem.elkady@aun.edu.eg

${ }^{1}$ Present Address: Department of Radiology, Faculty of Medicine, Assiut University, Assiut, Egypt

Full list of author information is available at the end of the article
}

biopsy [3, 4] and about $5 \%$ of individuals with isolated steatosis eventually developed cirrhosis [5].

Hepatic steatosis is so frequent histological feature (30-70\%) among chronic hepatitis $\mathrm{C}(\mathrm{CHC})$ patients compared with patients with other chronic hepatitis that it is considered of diagnostic significance [6,7]. Hepatic steatosis has been shown to worsen the course of liver disease in $\mathrm{CHC}$ patients, and it may reduce the efficacy of antiviral therapy and accelerate disease progression $[8,9]$. Furthermore, steatosis reduces hepatocellular functional reserve and contributes to postoperative hepatic failure after liver transplantation or resection [8]. Previous 
reports suggest that $\mathrm{HCV}$ infection changes the expression profile of lipid metabolism-associated factors in the liver and lipid accumulation in hepatocytes may be due to a direct effect of HCV, especially genotype 3 (G3) [10, 11]. Insulin resistance and steatosis are independent predictors of impaired response to antiviral treatment in chronic hepatitis C [10]. Thus, assessment of hepatic steatosis in $\mathrm{CHC}$ patients for clinical care requires not only diagnosis but also grading of its severity.

Non-targeted percutaneous liver biopsy with direct histological visualization is the current gold standard to diagnose hepatic steatosis. However, liver biopsy is an invasive maneuver with a lack of representation of the whole liver in a few samples. Moreover, most of the diffuse liver diseases are inherently heterogeneous renders biopsy suffering from sampling variability [12]. For measuring hepatic steatosis and reducing unneeded liver biopsy, multidetector computed tomography (MDCT) and magnetic resonance imaging (MRI) are noninvasive tools that allow both qualitative and quantitative assessment of fat content [13]. Previous studies investigated the quantification of hepatocellular lipid content $(\mathrm{HCL})$ using MRI and MDCT in G3-CHC patients [14, 15]. The highest prevalence of $\mathrm{HCV}$ infection is present in Egypt, with the majority of patients $(92.5 \%)$ infected with genotype 4 (G4) [16]; therefore, in this study, we aimed to evaluate the role of MDCT and MRI in the quantitative assessment and grading of hepatic steatosis in Egyptian G4-CHC patients also to evaluate the association between hepatic steatosis and fibrosis.

\section{Methods}

\section{Patients}

Between February 2015 and June 2018, a single-center cross-sectional study included 200 treatment-naive G4-CHC patients, who were candidates to receive antiviral therapy, recruited from Internal Medicine and Tropical Medicine clinics in our institution. They had to be between 18 and 70 years old and scheduled for liver biopsy. CHC was identified as persistent or intermittent elevation in alanine transaminase (ALT) or aspartate transaminase (AST) levels for more than 6 months with the presence of anti-HCV antibodies and positive serum HCV RNA [17].

Patients with evidence of alcohol abuse, diabetes mellitus, HBV co-infection, HIV co-infection, liver cell failure, hepatic focal lesions, splenectomy, any contraindication for MRI, e.g., the presence of a cardiac pacemaker, any contraindication for $\mathrm{CT}$ such as pregnancy or any contraindication of the liver biopsy were excluded from the study.

A total of 200 G4-CHC patients were consecutively recruited to this study. Forty-five patients were excluded as follows: eight patients had claustrophobia for MRI examination, 17 patients had newly discovered hepatic focal lesions and 20 patients refused a liver biopsy. The remaining 155 G4-CHC patients completed all the study examinations and statistical analysis, and their datasets were available as shown in Fig. 1.

The study was approved by our institutional ethical committee and was conducted in accordance with the provisions of the Declaration of Helsinki. Written informed consent was obtained from participants before enrolment.

\section{Clinical and diagnostic workup}

At study entry, a thorough medical history and physical examination were taken for data collection: age, gender, body mass index (BMI), co-morbidities, and severity of the liver disease. Blood samples were collected for laboratory investigations included complete blood count, liver, and kidney function tests. The studied patients underwent abdominal ultrasonography to exclude hepatic focal lesions and for guiding non-targeted percutaneous liver biopsy. Both MDCT and MRI were done, and then, liver biopsy was done within a short time interval (less than 15 days) under local anesthesia according to standard procedures.

\section{Imaging modalities}

All the patients underwent MDCT and MRI examination of the liver in the radiology department at our institution. No iodinated or gadolinium-based contrast agents were used. The diagnosis was confirmed for all the patients by percutaneous liver biopsy.

\section{Technique}

MDCT

All patients were examined in the supine position using 16 multidetector rows CT scanner (GE Lightspeed, GE Healthcare). No special preparation was needed. The non-contrast scan was obtained to cover the upper abdomen with the following parameters: $120 \mathrm{kV}$ and $350 \mathrm{mAs}$, with $0.5 \mathrm{~s}$ rotation time and 1.375 pitch. Then, data were reconstructed at $2.5 \mathrm{~mm}$ slice thickness at 2.5 $\mathrm{mm}$ intervals.

\section{MRI}

All patients were examined in the supine position using a $1.5 \mathrm{~T}$ magnet (Achieva, Philips Healthcare, the Netherlands) and SENSE Torso XL coil. No special preparation was needed. A compression belt was used to reduce respiratory motion. The following sequences cover the upper abdomen: (1) axial T2-weighted turbo spin echo (T2W_TSE)((time to repetition [TR] $405 \mathrm{msc}$, time to echo [TE] $80 \mathrm{~ms}$, flip angle $90^{\circ}$, matrix $256 \times 162$, field 


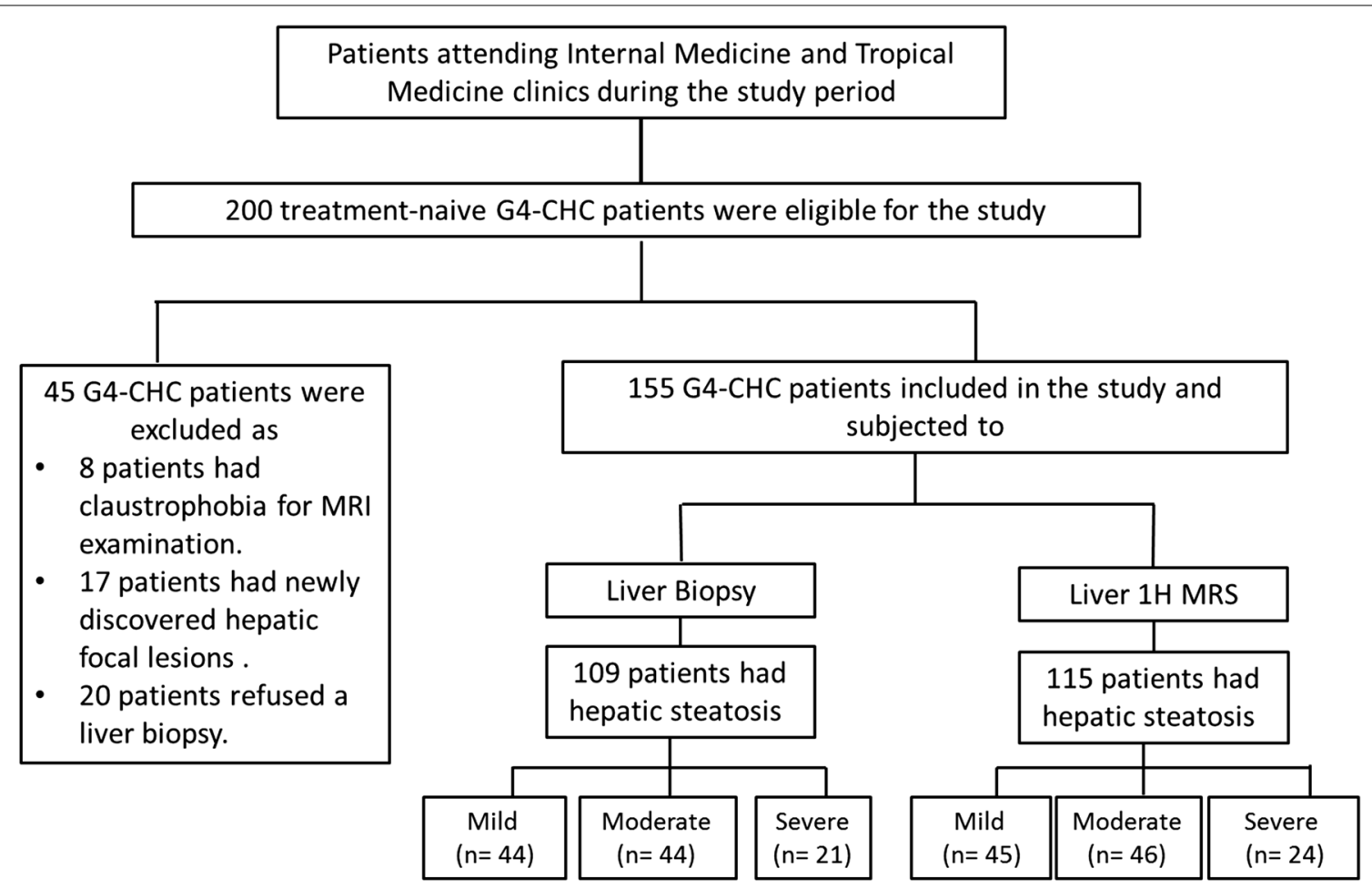

Fig. 1 Low chart of the patients enrolled in the present study

of view [FOV] $375 \mathrm{~mm}$, slice thickness $7 \mathrm{~mm}$, gap $1 \mathrm{~mm}$, number of signal average 1, scan time $13 \mathrm{~s}$ ), (2) axial selective adiabatic inversion recovery (SPAIR); fat suppressed images (time to repetition [TR] $520 \mathrm{msc}$, time to echo [TE] $80 \mathrm{~ms}$, flip angle $90^{\circ}$, matrix $256 \times 162$, field of view [FOV] $375 \mathrm{~mm}$, slice thickness $7 \mathrm{~mm}$, gap $1 \mathrm{~mm}$, number of signal average 1 , scan time $13 \mathrm{~s}$ ), (3) the dual-echo axial breath-hold T1-based gradient echo (GRE) imaging (in-phase/out-of-phase, IP/OP) routinely used for estimating liver fat (repetition time of $128 \mathrm{~ms}$; echo time of $6.9 \mathrm{~ms}$ for OP images and $4.6 \mathrm{~ms}$ for IP images; flip angle, $80^{\circ}$; section thickness, $7 \mathrm{~mm}$; matrix size, $192 \times 188$; FOV, $375 \mathrm{~mm}$ ), (4) single-voxel proton (1H) MR spectroscopy $\left({ }^{1} \mathrm{H}-\mathrm{MRS}\right)$ using point-resolved spectroscopy (PRESS) with long TR values after automatic shimming and it was acquired during free breathing. A localization voxel of $20 \times 20 \times 20 \mathrm{~mm}^{3}$ in the right hepatic lobe (V, VI, or VII segments) while avoiding large vessels, bile ducts, and liver edges (with a margin of $1-2 \mathrm{~cm}$ ) in all three anatomic planes on the scout images. MRS data were obtained during single breath holding. The other scan parameters were as follows: TE, $30 \mathrm{~ms}$; TR, $4000 \mathrm{~ms}$; bandwidth, $1000 \mathrm{~Hz}$; the number of acquisitions, two; water suppression, off; and acquisition time, $8 \mathrm{~s}$, and (v) diffusion-weighted imaging (DWI), transverse echoplanar. Parallel imaging was performed with SENSE technology. Multiple breath-hold techniques were done, each lasting $20 \mathrm{~s}$, and were performed to cover the entire liver and the typical acquisition time was $80 \mathrm{~s} . b$ values of $0,300,600 \mathrm{~s} / \mathrm{mm}^{2}$ were used.

\section{Analysis of images}

Two radiologists with 18 and 10 years of experience in radiology revised the results of the MDCT and MRI blinded to the results of the liver histopathologic evaluation. All measurements were taken by both radiologists independently; then, one value was taken in consensus for each analysis.

1. Unenhanced CT, a qualitative estimation of liver fat is performed by comparing the attenuation of the liver with that of the spleen. For fat quantification, both hepatic attenuation measurement in Hounsfield units and calculation of the hepatic attenuation index using region-of-interest (ROI) measurement of hepatic and splenic attenuation. A liver-to-spleen attenuation ratio of $\leq 1.1$ was used to assess hepatic steatosis [18].

2. Dual-echo T1-GRE imaging utilizes the difference in the resonance frequency of protons in water and protons in fat to detect and measure hepatic fat content by signal intensities measured in corresponding 
regions of interest on IP and OP images. An internal reference (spleen) was used to correct the hepatic signal intensity values. The hepatic fat fraction is calculated by comparing the signal intensities on IP and OP images $[19,20]$.

$$
\text { Fat signal fraction }=S_{\mathrm{ip}}-s_{\mathrm{op}} / 2 S_{\mathrm{ip}}
$$

where $S_{\text {IP }}$ is the net hepatic signal on IP images and $S_{\mathrm{OP}}$ is the net hepatic signal on OP images.

Fat signal percentage $=100 \times \operatorname{liver} S_{\mathrm{IP}} /$ spleen $S_{\mathrm{IP}}$

$$
\text { - liver } S_{\mathrm{OP}} / \text { spleen } S_{\mathrm{OP}} / 2 \times \operatorname{liver} S_{\mathrm{IP}} / \text { spleen } S_{\mathrm{IP}}
$$

where $S_{\text {IP }}$ is the ratio of hepatic signal intensity to splenic signal intensity on IP images and $\mathrm{S}_{\mathrm{OP}}$ is the ratio of hepatic signal intensity to splenic signal intensity on OP images.

3. Frequency-selective fat saturation

The fraction of relative signal intensity loss on the T2-weighted image without fat suppression (FS) and with a T2-weighted image with FS calculated as follows [21]

fat percentage in liver $(\mathrm{HFP})=$ nonFS - FS/nonFS $\times 10$

4. Proton $\left[{ }^{1} \mathrm{H}\right]$ MR spectroscopy $\left({ }^{1} \mathrm{H}\right.$-MRS)

Postprocessing of raw data from MRS was done using a vendor postprocessing package software. Manual phase adjustment was used, as well as the spectral shift of the display before integration. Lipid and water peak integral areas were obtained at set frequency limits and then corrected for relaxation. The total hepatic triglyceride content (TGC) is calculated by summing the individual lipid peaks in the $0.9-3.0$ parts per million ( $\mathrm{ppm}$ ) region of the MR spectrum to obtain the total lipid peak area (TLPA). The sum of fat and water peaks calculated to obtain proton density fat fraction (PDFF) as follows [22]
The apparent diffusion coefficient (ADC) map was generated on a voxel-by-voxel basis by a commercially available software package (Philips MR workspace, Philips Medical System; Eindhoven, the Netherlands). Regions of interest of $2 \mathrm{~cm}^{2}$ were placed in each segment of the right lobe avoiding areas of artifact or vessels. The left lobe segments were excluded from our measurements due to the possible cardiac motion artifacts. The mean ADC value was calcu-

$\mathrm{PDFF}=$ fat signal peak area $(0.9-3 \mathrm{ppm}) /$ fat signal peak areas + water peak area $)$

However, the MRS spectra acquired in the left lobe in most of the subjects were corrupted by the artifact and not considered of sufficient quality to include in the analysis, and thus, measurements are most often only obtained in the right lobe.

Krššák et al. [14] yielded following staging-0: no steatosis resulting in less than $3.1 \%$ of MRS signal; stage 1 : mild resulting in the range of $3.1-5.0 \%$ of MRS signal; stage 2: moderate resulting in the range of 5.0$6.9 \%$ of MRS signal; and stage 3: severe resulting in more than $6.9 \%$ of MRS signal.

5. DWI lated for each case to infer hepatic fibrosis.

\section{Liver biopsy and histopathological analysis}

For histological analysis, the samples were routinely processed, formalin-fixed and paraffin-embedded, stained with hematoxylin/eosin for steatosis and inflammation, and Masson's trichrome stain for assessment of fibrosis. The histopathologic grades provided by the pathologist according to the nonalcoholic steatohepatitis (NASH) Clinical Research Network Scoring System definitions [23]. Steatosis, ballooning, lobular inflammation, and fibrosis were staged: steatosis involving $<5 \%$ of cells (S0, no steatosis), 5-33\% (S1, mild), >33-66\% (S2, moderate), and $>66 \%$ (S3, severe) of hepatocytes. Ballooning was graded as none (0), few balloon cells (1), and many cells/ prominent ballooning (2). Lobular inflammation was graded as no foci $(0$, none), $<2$ foci $(1$, mild), $2-4$ foci $(2$, moderate), and $>4$ foci per $200 \times$ field ( 3 , marked). Fibrosis was staged as none (F0), portal fibrosis: fibrous portal expansion (F1), periportal fibrosis (F2), bridging fibrosis, and distorted architecture (F3), and cirrhosis (F4). The diagnosis of non-alcoholic fatty liver disease (NAFLD) was made if steatosis was $\geq 5 \%$ and either ballooning or lobular inflammation or both were absent. The diagno- sis of NASH was made when steatosis was $\geq 5 \%$ and ballooning and lobular inflammation were present [24].

\section{Statistical analysis}

All statistical analyses were carried out using SPSS for Windows version 16 (IBM Corp., Armonk, NY, USA) and the MedCalc program. Inter-rater agreement for each test was calculated using Cohen's kappa coefficient $(j)$ which is calculated as follows: $j=(\mathrm{p} 0 \mathrm{pe}) /(1 \mathrm{pe})$, where $\mathrm{p} 0$ is the observed proportion of agreement and pe is the expected proportion of agreement. Quantitative data are expressed as mean \pm standard deviation or median 
and the range for normally or abnormally distributed data and qualitative data were expressed as a percentage. Spearman's rank correlation coefficient $(r)$ was used to find correlations. The receiver operating characteristic (ROC) curves were plotted to measure and compare the performance of different noninvasive imaging parameters in predicting hepatic steatosis and its grades. The best cutoff values were chosen to calculate sensitivity, specificity, positive (PPV) and negative (NPV) predictive value, positive and negative likelihood ratio (+LR, $-\mathrm{LR})$ for predicting hepatic steatosis. All tests were two-tailed and statistical significance was assessed at $<0.05$.

\section{Results}

\section{Characteristics of the study patients}

The mean age of the total 155 patients was $43.2 \pm 12.9$ years and the majority of them were males (119/155, 76.8\%). Their mean BMI was $25.6 \pm 2.9 \mathrm{~kg} /$ $\mathrm{m}^{2}$ where, more than half of the cases were overweight $\geq 25 \mathrm{~kg} / \mathrm{m}^{2}(87 / 155,56 . \%)$. Further clinical and laboratory characteristics of the studied patients are summarized in Table 1

Histologically, hepatic steatosis was found in 109 (70.3\%) of $155 \mathrm{CHC}$ patients. The degree of hepatic steatosis was mild in 44, moderate in 44, and severe in 21 cases. Furthermore, staging for liver fibrosis showed different stages (F1: $n=54, \mathrm{~F} 2: n=62, \mathrm{~F} 3: n=13, \mathrm{~F} 4: n=26)$.

\section{Characteristics of imaging modalities and their correlation with histopathological data}

We found that 78 cases $(50.3 \%)$ had a low CT ratio $(\leq 1.1)$. We found no correlation between the $\mathrm{CT}$ ratio and pathological grading of hepatic steatosis $(r=-0.090$, $p=0.614)$.

As regarding MRI modalities, $\mathrm{T} 1$-fat fraction ranged between ( -32.5 to $30.4 \%$ ) throughout the liver with the median of $-13.5 \%$ and $3.2 \%$ for the voxel placed in the anterior part of the right liver lobe. Furthermore, the median total proton density fat fraction was $12.5 \%$

Table 1 Demographic and clinical characteristics of the study patients with genotype-4 chronic hepatitis C

\begin{tabular}{|c|c|}
\hline Variables & Number of patients $=115$ \\
\hline Age (years, mean \pm SD \& range) & $43.2 \pm 12.9(21-62)$ \\
\hline Sex (male/female) & $119 / 36(76.8 / 23.2 \%)$ \\
\hline$B M I\left(\mathrm{~kg} / \mathrm{m}^{2}\right.$, mean $\left.\pm S D\right)$ & $25.6 \pm 2.9$ \\
\hline Average weight $(\mathrm{BMI}<25)$ & $68(43.9 \%)$ \\
\hline Overweight (BMI 25-30) & $87(56.1 \%)$ \\
\hline Obese $(\mathrm{BMI}>30)$ & 0 \\
\hline Serum albumin ( $g / d L$, mean $\pm S D)$ & $3.8 \pm 0.7$ \\
\hline Serum bilirubin (mg/dL, median \& range) & $1.4(0.6-5.8)$ \\
\hline $\mathrm{ALT}(\mathrm{U} / \mathrm{L}$, mean $\pm \mathrm{SD})$ & $41.5 \pm 20.3$ \\
\hline $\mathrm{AST}(\mathrm{U} / \mathrm{L}$, mean $\pm \mathrm{SD})$ & $38.9 \pm 18.3$ \\
\hline $\operatorname{ALP}(\mathrm{U} / \mathrm{L}$, mean $\pm \mathrm{SD})$ & $119.4 \pm 48.7$ \\
\hline Platelet count $\left(10^{3} / \mu \mathrm{L}, \mathrm{U} / \mathrm{L}\right.$, mean $\left.\pm \mathrm{SD}\right)$ & $201.7 \pm 72.2$ \\
\hline HCV RNA (IU/mL, median \& range) & $4.5 \times 10^{5}\left(9 \times 10^{3}-8 \times 10^{6}\right)$ \\
\hline \multicolumn{2}{|l|}{ Histopathological data } \\
\hline Fibrosis stage (F1/F2/F3/F4) & $54 / 62 / 13 / 26(34.8 / 40 / 8.4 / 16.8)$ \\
\hline Hepatitis grades (G1/G2/G3) & $68 / 58 / 29(43.9 / 37.4 / 18.7)$ \\
\hline Steatosis (no/mild/moderate/severe) & 23/44/44/21 (29.7/28.4/28.4/13.5) \\
\hline \multicolumn{2}{|l|}{ MDCT data } \\
\hline CT ratio (mean \pm SD, range) & $1.1 \pm 0.2(0.3-1.4)$ \\
\hline \multicolumn{2}{|l|}{ MRI data } \\
\hline T1-fat fraction (median \& range) & $-13.5(-32.5$ to 30.4$)$ \\
\hline Fat percentage (median \& range) & $4.8(-5.2$ to 33.4$)$ \\
\hline T2 fat suppression (median \& range) & $0.1(-22.5$ to 22.2$)$ \\
\hline Proton density fat fraction\% (PDFF) (median \& range) & $6.2(0.6-35.2)$ \\
\hline ADC for hepatic fibrosis ( $\times 10^{-3} \mathrm{~mm}^{2} / \mathrm{s}$ ) (median \& range) & $1.2(0.97-1.4)$ \\
\hline
\end{tabular}

$A D C$ apparent diffusion coefficient, $A L T$ alanine aminotransferase, $A L P$ alkaline phosphatase, $A S T$ aspartate aminotransferase, $B M I$ body mass index, $S D$ standard deviation, MDCT multidetector computed tomography, MRI magnetic resonance imaging 
(1.26-70.43\%) throughout the right lobe of the liver providing a wide range of liver fat content (Table 1 ).

We found that proton density fat fraction was significantly correlated with the histopathologic staging of fibrosis $(r=0.707, p \leq 0.001)$, grading of steatosis $(r=0.953, p<0.001)$, and grading of hepatitis (lobular inflammation) $(r=0.791, p<0.001)$ and negatively correlated with ADC for hepatic fibrosis $(r=-0.476$ and $p=0.004)$, while the T1-fat fraction and fat percentage were correlated with steatosis grading $(r=0.380$, $p=0.027$ and $r=0.384, p=0.025$, respectively) as shown in Fig. 2. On the other hand, no correlation was found between fat suppression and steatosis grades $(r=0.088, p=0.620)$.
In addition, no correlations were found between age, gender, BMI and liver enzymes (ALT and AST), serum virological load and histological stages of steatosis, or the evaluated liver fat metrics of CT, and MRI $(p>0.05)$.

\section{Diagnostic performance of MDCT and MRI parameters for prediction of hepatic steatosis}

Based on the ROC curves, T1-fat fraction, Fat percentage and proton density fat fraction had good prognostic accuracy for the prediction of hepatic steatosis where proton density fat fraction yielded the highest AUC (0.958) and 95\% confidence interval (CI) (0.828-0.995, $p<0.001$ ), with $95.8 \%$ sensitivity and $90 \%$ specificity at a cutoff of $>4.95$ followed by T1-fat fraction (0.808) and fat percentage (0.702) as shown in (Table 2; Fig. 3a).
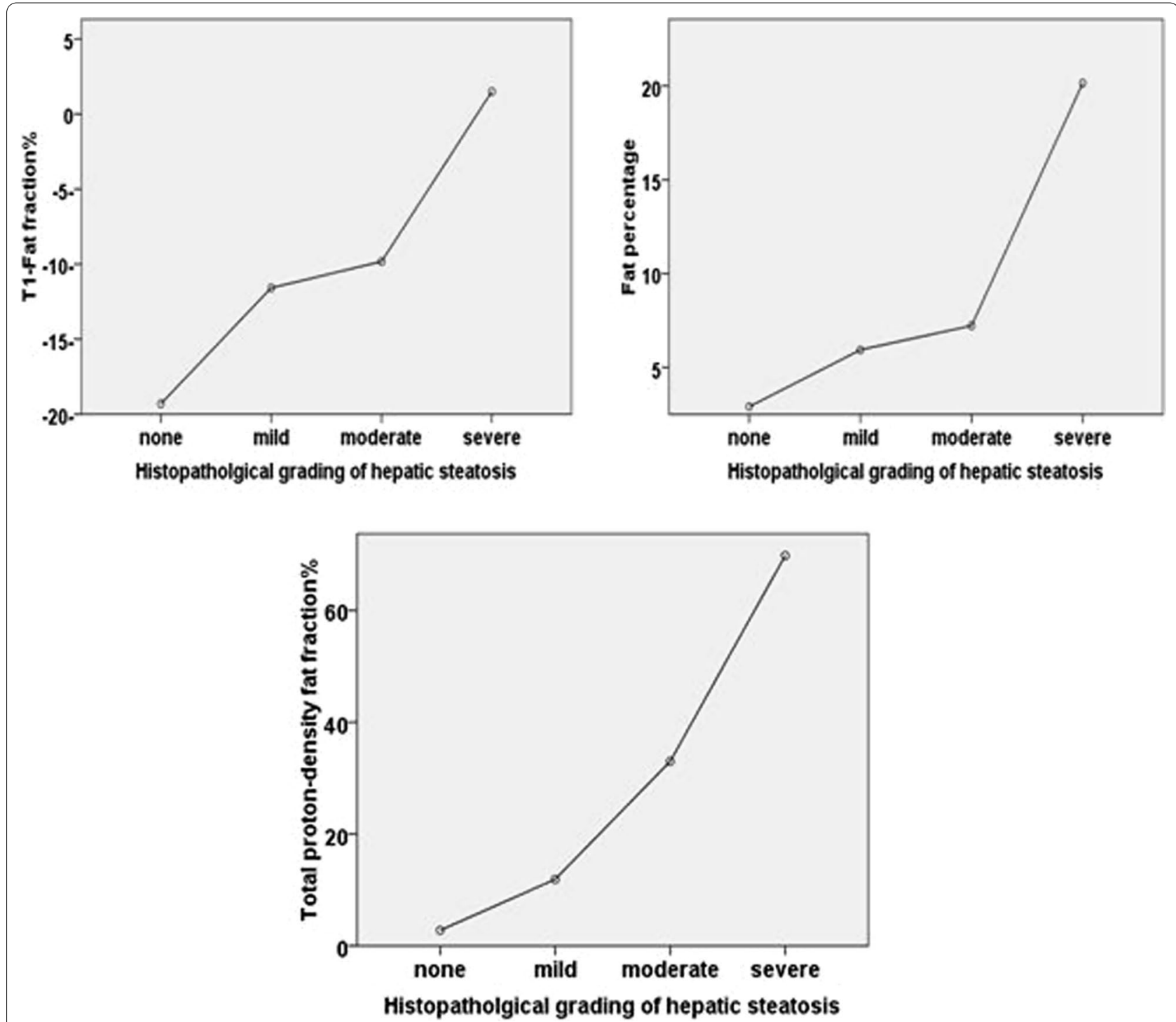

Fig. 2 Correlation between the histological hepatic steatosis grades and evaluated liver fat metrics of MRI. The figure shows increased liver fat metrics of MRI with increasing grades of steatosis 
Table 2 Diagnostic accuracy of magnetic resonance imaging (MRI) parameters to predict hepatic steatosis with the best predictive cutoffs

\begin{tabular}{|c|c|c|c|c|c|c|c|c|}
\hline & AUC $(95 \% \mathrm{Cl})$ & SE & $\mathrm{SP}$ & PPV & NPV & $+\mathrm{LR}$ & $-\mathrm{LR}$ & $p$ \\
\hline \multicolumn{9}{|l|}{ For the prediction of liver steatosis } \\
\hline T1-fat fraction $>-13.7 \%$ & $0.808(0.637-0.922)$ & 66.7 & 90 & 94 & 53.5 & 6.7 & 0.4 & $<0.001$ \\
\hline Fat percentage (>5.1\%) & $0.702(0521-0.846)$ & 54.2 & 80 & 86.4 & 42.7 & 2.7 & 0.6 & 0.030 \\
\hline Proton density fat fraction (>4.95\%) & $0.958(0.828-0.995)$ & 95.8 & 90 & 95.7 & 90.1 & 9.6 & 0.1 & $<0.001$ \\
\hline \multicolumn{9}{|l|}{ For the prediction of mild liver steatosis } \\
\hline T1-fat fraction $>-13.7 \%$ & $0.845(0.622-0.963)$ & 72.7 & 90 & 74.4 & 89.2 & 7.3 & 0.3 & $<0.001$ \\
\hline Fat percentage (>5.1\%) & $0.650(0.414-0.841)$ & 45.5 & 80 & 47.7 & 78.6 & 2.3 & 0.7 & 0.217 \\
\hline Proton density fat fraction (> 4.95\%) & $0.910(0.701-0.987)$ & 91 & 90 & 78.5 & 96.1 & 9.1 & 0.1 & $<0.001$ \\
\hline \multicolumn{9}{|c|}{ For the prediction of moderate liver steatosis } \\
\hline T1-fat fraction (>0.4\%) & $0.654(0.466-0.812)$ & 27.3 & 100 & 100 & 77.4 & - & 0.7 & 0.147 \\
\hline Fat percentage (> 2.8\%) & $0.652(0.463-0.810)$ & 90.9 & 38.1 & 37 & 91.3 & 1.5 & 0.2 & 0.154 \\
\hline Proton density fat fraction (> 8.44\%) & $0.931(0.782-0.988)$ & 100 & 85.7 & 73.7 & 100 & 7 & 0 & $<0.001$ \\
\hline \multicolumn{9}{|l|}{ For the prediction of severe liver steatosis } \\
\hline T1-fat fraction $(>6.2 \%)$ & $0.619(0.445-0.773)$ & 40 & 100 & 100 & 91.8 & - & 0.6 & 0.942 \\
\hline Fat percentage (>6.1\%) & $0.850(0.694-0.945)$ & 100 & 65.6 & 30.3 & 100 & 2.9 & 0 & 0.0742 \\
\hline Proton density fat fraction (> 20.4\%) & $0.975(0.861-995)$ & 100 & 93.8 & 70.7 & 100 & 16 & 0 & $<0.001$ \\
\hline
\end{tabular}

$A U C$ area under the receiver operating characteristic curve, $+\angle R$ positive likelihood ratio, $-L R$ negative likelihood ratio, NPV negative predictive value, $P P V$ positive predictive value, SP specificity, SE sensitivity

The ROC curves evaluated the diagnostic accuracies of these MRI parameters to determine which parameter would have the most clinical utility to predict different stages of liver steatosis as defined by histological stages. For predicting mild steatosis (Fig. 3b), the AUC was greatest for the total proton density fat fraction $(0.910)$ followed by T1-fat fraction $(0.845)$, then the fat percentage $(0.650)$. For predicting moderate steatosis (Fig. 3c), the AUC was greatest for the total proton density fat fraction $(0.931)$, followed by the T1-fat fraction (0.654) and fat percentage (0.652). To predict severe steatosis (Fig. 3d), the AUC was greatest for total proton density fat fraction $(0.975)$ followed by fat percentage (0.850) then T1-fat fraction (0.619).

In addition, using the ROC curves, we calculated the cutoff values of the total proton density fat fraction to discriminate different steatosis grades (Table 2). With a cutoff value $>4.95 \%$, total fat fraction $\%$ had $91 \%$ sensitivity, 90\% specificity, $78.5 \%$ PPV, and $96.1 \%$ NPV for the prediction of mild steatosis. At a cutoff value $>8.4$, total fat fraction\% had $100 \%$ sensitivity, $85.7 \%$ specificity, $73.7 \%$ PPV, and $100 \%$ NPV for the prediction of moderate steatosis. Furthermore, at a cutoff value $>20.4 \%$ total fat fraction $\%$ had $100 \%$ sensitivity, $93.8 \%$ specificity, $70.7 \%$ PPV, and $100 \%$ NPV for the prediction of severe steatosis.

On comparison of steatosis grading by histology and ${ }^{1} \mathrm{H}$-MRS, we found an agreement between these methods in $74.2 \%$ of patients as shown in (Table 3 ) with the highest percentage of correct diagnosis in mild steatosis $(75 \%)$ and the lowest percentage of correct diagnosis in moderate steatosis $(65.9 \%)$. The distribution of steatosis grading by histology and ${ }^{1} \mathrm{H}$-MRS in different fibrosis stages was shown in (Table 4) (Figs. 4, 5).

\section{Interobserver reproducibility of MDCT and MRI in quantitative assessment of hepatic steatosis}

As regards the interrater agreement in this study, there was substantial agreement in the qualitative estimation of liver fat in non-enhanced MDCT examinations (0.78), and almost perfect agreement in quantitative fat assessment in MDCT, dual-echo T1-GRE imaging, frequencyselective fat saturation, proton $[1 \mathrm{H}]$ MR spectroscopy, and ADC measurements $(0.85-0.97)$ between the two readers.

\section{Discussion}

This prospective study showed the diagnostic performance of liver fat metrics of MRI as noninvasive methods for the detection of hepatic steatosis in Egyptian G4-CHC patients. Elaborating reliable models to predict liver steatosis in those patients remains a challenge for hepatologists. Identification of significant steatosis (moderate and severe) is an important parameter for antiviral treatment.

Out of the 155 patients included in our study, 109 patients (70.3\%) showed evidence of steatosis on histopathological examination of liver biopsies that were 

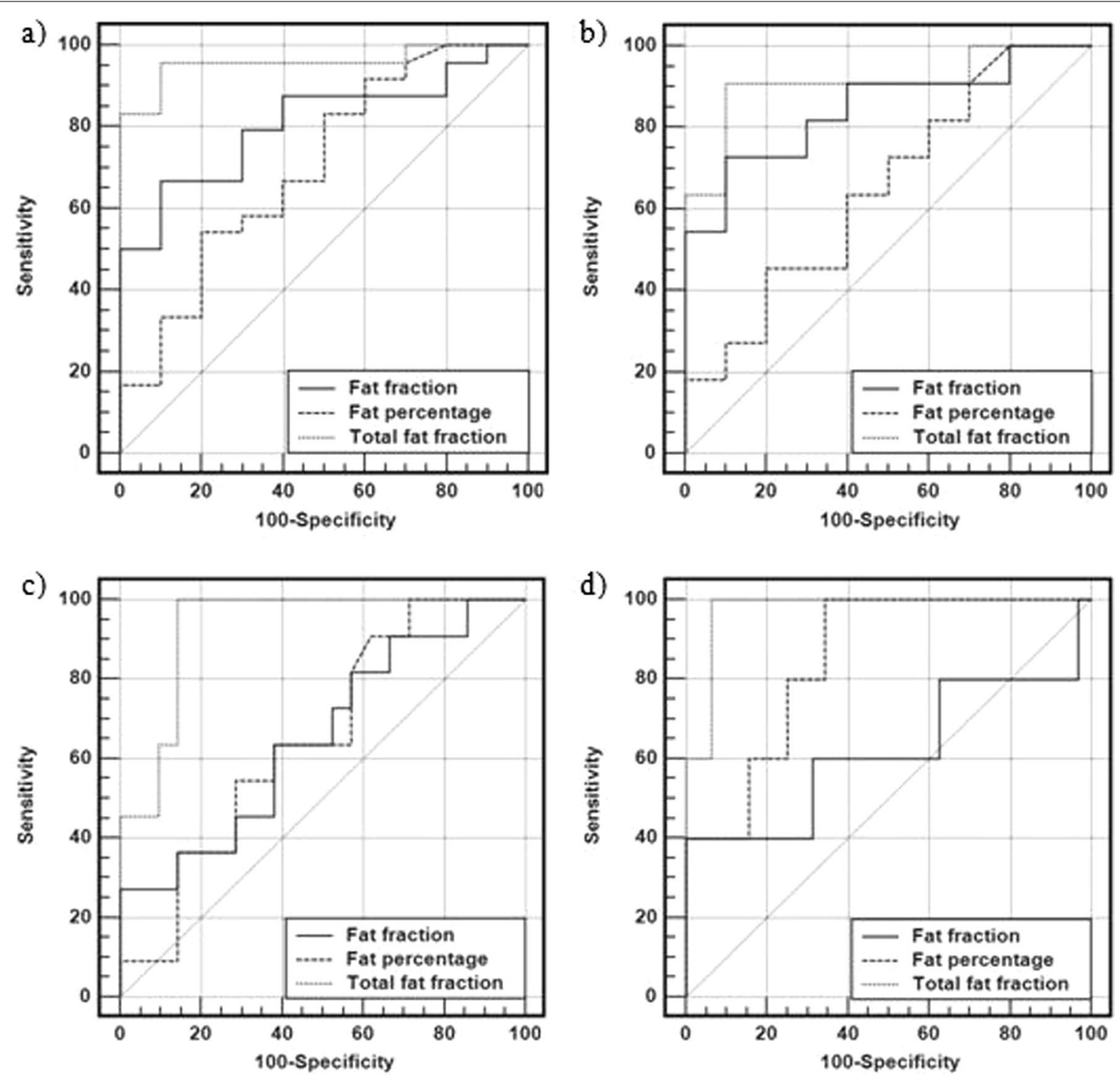

Fig. 3 Area under the receiver operating characteristic curve (AUC) of MRI parameters to predict a liver steatosis, $\mathbf{b}$ mild steatosis, $\mathbf{c}$ moderate steatosis, $\mathbf{d}$ severe steatosis, whereas proton density fat fraction had the highest AUCs in the prediction of steatosis and its different grades

Table 3 Comparison between hepatic steatosis staging by histology and $1 \mathrm{H}$ MRS

\begin{tabular}{lcccc}
\hline $\begin{array}{l}\text { Liver steatosis } \\
\text { grades by } \\
\text { histology }\end{array}$ & \multicolumn{4}{l}{ Liver steatosis grades by $\mathbf{1 H}^{\mathrm{a}}$ MRS $^{\mathrm{a}}$} \\
\cline { 2 - 5 } & No $(\boldsymbol{n}=\mathbf{4 0 )})$ & Mild $(\boldsymbol{n}=\mathbf{4 5})$ & $\begin{array}{l}\text { Moderate } \\
(\boldsymbol{n}=\mathbf{4 6})\end{array}$ & $\begin{array}{l}\text { Severe } \\
(\boldsymbol{n}=\mathbf{2 4})\end{array}$ \\
\hline None $(n=46)$ & 36 & 6 & 4 & 0 \\
Mild $(n=44)$ & 4 & 33 & 7 & 0 \\
Moderate $(n=44)$ & 0 & 6 & 29 & 9 \\
Severe $(n=21)$ & 0 & 0 & 6 & 15 \\
\hline
\end{tabular}

${ }^{a}$ Cutoff values for hepatic steatosis were 5,33 , and $66 \%$ of involved hepatocytes for histology and $4.95,8.4$, and $20.3 \%$ of MRS signal for 1 H MRS method. In $74 \%$ of patients an agreement between

histological and 1H MRS steatosis assessment was achieved within the range of previous studies $[25,26]$ showing that hepatic steatosis is a feature of G4-HCV infection.

Consistent with earlier studies [27-30], we found liver fat metrics of ${ }^{1} \mathrm{H}$-MRS correlated with the histological grading of hepatic steatosis in $\mathrm{CHC}$ patients. Kršsák et al.[14] stated that a significant correlation between ${ }^{1} \mathrm{H}$-MRS and histological steatosis was further confirmed by biochemical analysis of extracted tissue samples.

In this study, liver fat metrics of ${ }^{1} \mathrm{H}$-MRS had the potential to predict hepatic steatosis, whereas the diagnostic accuracy of MRS total proton density fat fraction with an AUC of $0.958,95.8 \%$ sensitivity, 90\% specificity, $95.7 \%$ PPV, and $90.1 \%$ NPV at a cutoff $>4.95 \%$. Our 
Table 4 Distribution of hepatic steatosis grade as assessed by histology /MRS in different fibrosis stages

\begin{tabular}{|c|c|c|c|c|}
\hline \multirow[t]{2}{*}{ Liver fibrosis stages } & \multicolumn{4}{|c|}{ Liver steatosis grades by histology/MRS } \\
\hline & No $(n=46 / 40)$ & Mild $(n=44 / 45)$ & Moderate $(n=44 / 46)$ & $\begin{array}{l}\text { Severe } \\
(n=21 / 24)\end{array}$ \\
\hline $\mathrm{F} 1(N=54)$ & $46 / 36$ & $6 / 18$ & $2 / 0$ & 0 \\
\hline $\mathrm{F} 2(N=62)$ & $0 / 4$ & $38 / 27$ & $24 / 31$ & 0 \\
\hline $\mathrm{F} 3(N=13)$ & $0 / 0$ & $0 / 0$ & $4 / 10$ & $9 / 3$ \\
\hline $\mathrm{F} 4(N=26)$ & 0 & 0 & $14 / 5$ & $12 / 21$ \\
\hline
\end{tabular}

results were supported by Rastogi et al. [27] who demonstrated that MRS had an AUC of 0.959 with $94 \%$ sensitivity, 97\% specificity, 95\% NPV, and 96\% accuracy to diagnose liver steatosis at a cutoff value of 6.27.

We found that the total proton density fat fraction showed the best diagnostic performance for predicting different grades of steatosis $(\mathrm{AUC}=0.910,0.931$, and 0.975 for mild, moderate, and severe steatosis, respectively) compared to the other MRI metrics; fat fraction and percentage. Moreover, at cutoff $>4.95,{ }^{1} \mathrm{H}$-MRS can discriminate mild steatosis from no steatosis (91\% sensitivity, 90\% specificity, 78.5\% PPV and 96.1\% NPV). It can predict moderate steatosis (100\% sensitivity, $85.7 \%$ specificity, $73.7 \%$ PPV and 100\% NPV) with a cutoff value $>8.4$. Additionally, it can predict severe steatosis with a cutoff value $>20.4(100 \%$ sensitivity, $93.8 \%$ specificity, $70.7 \%$ PPV, and 100\% NPV). Kršsák et al. [14] assessed grades of hepatic steatosis based on ${ }^{1} \mathrm{H}$-MRS results using different
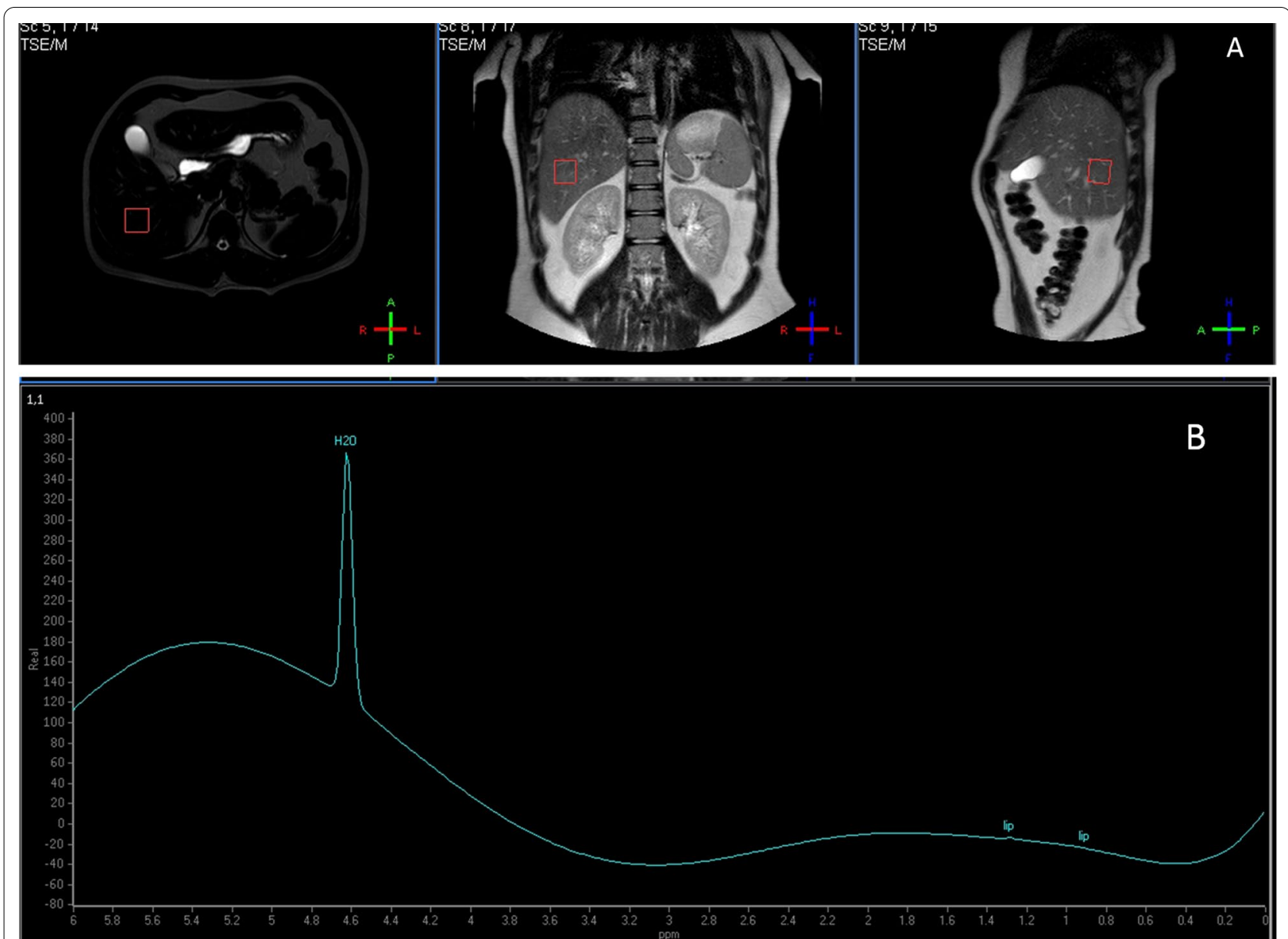

Fig. 4 Multiple 1H-MRS of different patients with CHC. A Localizer three plane images of 1H-MRS show a voxel located at segment VI of the right hepatic lobe. $\mathbf{B}$ non-steatosis, $\mathbf{C}$ mild steatosis spectrum, and $\mathbf{D}$ severe steatosis spectrum show lipid peaks at 0.9-1.3 ppm and $\mathrm{H} 2 \mathrm{O}$ peak at 4.7 ppm. These spectra show reduced water peak with increase steatosis 

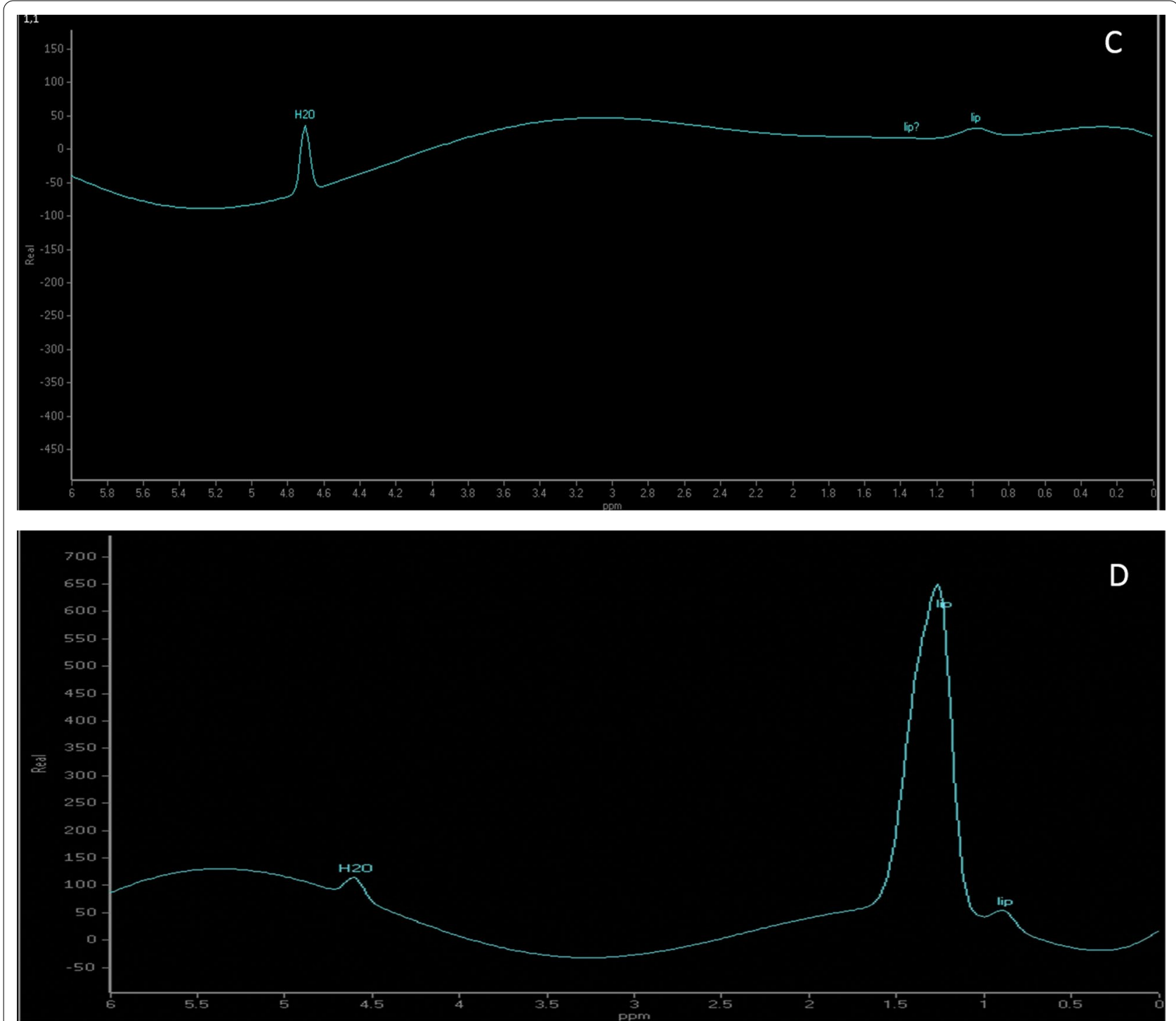

Fig. 4 continued

cutoff values; $<3.1 \%, 3.1-5.0 \%, 5.0-6.9 \%$, and $>6.9 \%$ for no, mild, moderate, and severe steatosis, respectively. The high cutoff values for the diagnosis of significant steatosis (moderate and severe) in our study may be attributed to the presence of hepatic fibrosis affecting the imaging of steatosis.

Noureddin et al. [31] reported that ${ }^{1} \mathrm{H}-\mathrm{MRS}$ was a reliable noninvasive method to evaluate the whole liver parenchyma including a complete assessment of liver fat content (FC). This is particularly relevant in patients with heterogeneous hepatic steatosis in which sensitivity of liver biopsy is limited as less than $1 / 50,000$ th of the liver is available for histopathological examination [32].

The current study showed no correlation between the $\mathrm{CT}$ ratio and histopathological grading of hepatic steatosis. Contrary to our finding, Rastogi, et al. [27] reported that $\mathrm{CT}$ fat quantification correlated well with liver biopsy results $(r=0.715)$; however, it was inferior to MR methods for liver fat estimation. It has further limitations in providing semiquantitative nature of findings rather than discrete values for fat content. The poor performance of the CT ratio in detecting steatosis might be due to the small number of $\mathrm{CHC}$ patients included in this study.

In this study, we found that hepatic fat content measured by proton density fat fraction correlated with lobular inflammation. These findings were consistent with previous studies indicating an influence of steatosis on the necroinflammatory activity of $\operatorname{HCV}[33,34]$. 


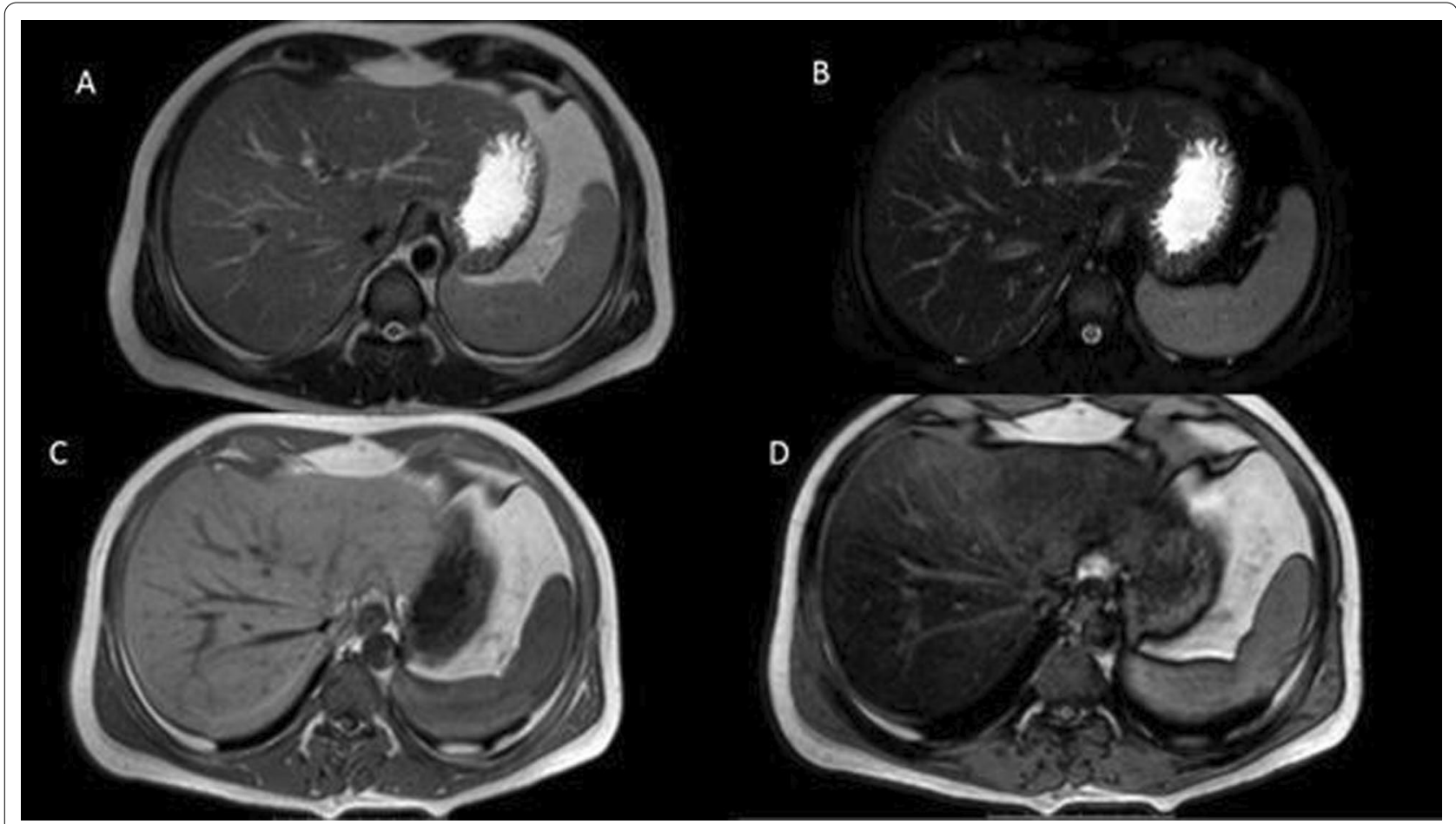

Fig. 5 A 30-year-old male patient with CHC A axial T2WI, B axial SPIR, C axial T1-in-phase, D T1-out-of-phase. A, B Signal intensity of the liver drops compared to spleen because the fat-saturated pulse suppresses the signal from fat within the liver. C, D Marked signal dropout on out-of-phase imaging indicating the presence of diffuse steatosis with calculated fat fraction and fat percentage about 30.40 and 33.44 , respectively, indicating severe steatosis

In $\mathrm{CHC}$, precise mechanisms leading to hepatic steatosis are complex and not well characterized, e.g., oxidative stress, cytokine release, inflammation, insulin resistance, and impaired lipid and carbohydrate metabolism may initiate the development of steatosis, worse fibrosis, and reduce therapeutic response. Steatosis in hepatitis $\mathrm{C}$ appears to be genotype-specific [35]. It is predominantly cytopathic in genotype 3 (G3) in which a sustained virological response is associated with hepatic steatosis reduction [15] and metabolic in non-G3 hepatitis $C$ that may reduce the success of antiviral therapy [36]. Regarding genotype 4, hepatic steatosis was mostly associated with metabolic factors, similar to those in genotype 1; however, the possibility of the presence of viral-induced steatosis was also accused [37, 38].

Fishbein et al. [39] showed that hepatic MRI, based upon chemical shift imaging, was able to accurately quantify the hepatic FC even in patients with significant hepatic fibrosis. Concomitantly, in our study, ${ }^{1} \mathrm{H}-$ MRS; total proton density fat fraction, could assess hepatic steatosis in $76.6 \%$ of $\mathrm{CHC}$ patients with hepatic fibrosis. In line with previous studies [40, 41], we reported a significant correlation between quantification of hepatic FC based on total proton density fat fraction and hepatic fibrosis (diagnosed histologically and by $\mathrm{ADC}$ ) in $\mathrm{CHC}$ patients. These findings were matched with previous studies. Moreover, Kršsák et al. [14] and Orlacchio et al. [28] revealed uniform distribution of steatosis grades across all fibrosis stage groups indicating that hepatic steatosis may accelerate liver fibrosis. Hepatic steatosis may induce fibrosis through insulin resistance and oxidative stress leading to lipid peroxidation and cytokine release [8]. Also, prolonged lipid storage can result in inflammatory reactions and loss of metabolic competence [42]. Modaresi Esfeh and Ansari-Gilani [43] revealed that steatosis in $\mathrm{CHC}$ patients was associated with more severe histological injury and higher fibrosis scores, suggesting that fat in the liver is biologically active tissue. Unlike our findings, Cho et al. [44] reported that an increased hepatic metabolite/fat ratio, as assessed by localized ${ }^{1} \mathrm{H}$-MRS, correlated with fibrosis staging suggesting decreased steatosis in higher fibrosis stages.

Although this study is one of the few studies which investigated liver fat metrics of CT and MRI in G4-CHC patients with hepatic fibrosis, it has some limitations. This series was a small-sized sample and a single-center study, so, the sample may not exactly represent the general population of $\mathrm{CHC}$ patients. Hence, further multicenter studies with larger populations are needed to confirm these 
results, validate their usefulness in clinical practice, and assess the dynamic changes in liver fat metrics of MRI during antiviral therapy. Although the principle of MRS to quantify hepatic steatosis is straightforward, there were some biases in its acquisition, e.g., T1 and T2 relaxation effects were well-known biases of MRS to evaluate hepatic steatosis in addition to the presence of excessive iron. In addition, MDCT, however, had a limited diagnostic accuracy for detecting mild hepatic steatosis in addition to potential hazard of radiation exposure.

\section{Conclusions}

${ }^{1} \mathrm{H}$-MRS had a good diagnostic performance in diagnosis and quantification of hepatic steatosis whereas ${ }^{1} \mathrm{H}$-MRS; a proton density fat fraction has the highest diagnostic accuracy as a noninvasive quantitative modality for hepatic steatosis and its different grades that may influence the course of chronic HCV infection and possibly its response to the antiviral therapy. It may have important clinical applicability, especially in those liver biopsies, which cannot be done.

\begin{abstract}
Abbreviations
MDCT: Multidetector computed tomography; MRI: Magnetic resonance imaging; G4-CHC: Genotype 4-chronic hepatitis C; CHC: Chronic hepatitis C; 1 H-MRS: Proton magnetic resonance spectroscopy; AUC: Area under curve; NAFLD: Non-alcoholic fatty liver disease; HIV: Human immonodeficiency virus; CV: Hepatitis C virus; CL: Hepatocellular lipid content; ALT: Alanine transaminase; AST: Aspartate transaminase; RNA: Ribonucleic acid; HBV: Hepatitis B virus; BMI: Body mass index; TSE: Turbo spin echo; TR: Time to repetition; TE: Time to echo; FOV: Field of view; SPAIR: Selective adiabatic inversion recovery; GRE: Gradient echo; IP: In-phase; OP: Out-of-phase; PRESS: Point-resolved spectroscopy; DWI: Diffusion weighted imaging 4; ROI: Region of interest; $S_{o p}$ : The net hepatic signal on OP images; $S_{1 P}$ : Net hepatic signal on IP images; FS: Fat suppression; HFP: Fat percentage in liver; TGC: Total hepatic triglyceride content; TLPA: Total lipid peak area; PDFF: Proton density fat fraction; ADC: Apparent diffusion coefficient; NASH: Non-alcoholic steatohepatitis; FC: Fat content.
\end{abstract}

\section{Acknowledgements}

Not applicable.

\section{Authors' contributions}

GSS designed the study, collected and analyzed the data, and drafted and revised the manuscript. EAH and HMl designed the study, recruited the patients, collected the data and revised the manuscript. RM interpreted the pathological data. NKI and MAG did laboratory work and interpreted the data. RME designed the study, interpreted the data, drafted and revised the manuscript, and managed the publication. All authors have read and approved the manuscript.

\section{Funding}

This research did not receive any specific grant from funding agencies in the public, commercial, or not-for-profit sectors.

\section{Availability of data and materials}

The datasets used and/or analyzed during the current study are available on reasonable request.

\section{Declarations}

\section{Ethics approval and consent to participate}

This study has been approved by the ethical committee of the Faculty of Medicine, Assiut University. The approval number is not applicable. A written consent was obtained from each study participant.

\section{Consent for publication}

Not applicable.

\section{Competing interests}

The authors declare that they have no competing interests.

\section{Author details}

${ }^{1}$ Present Address: Department of Radiology, Faculty of Medicine, Assiut University, Assiut, Egypt. ${ }^{2}$ Department of Gastroenterology and Tropical Medicine, Assiut University, Assiut, Egypt. ${ }^{3}$ Department of Internal Medicine, Assiut University, Assiut, Egypt. ${ }^{4}$ Department of Pathology, Assiut University, Assiut, Egypt. ${ }^{5}$ Department of Biochemistry, Assiut University, Assiut, Egypt. ${ }^{6}$ Department of Radiology and Medical imaging, College of Medicine, Taibah University, Madinah, Saudi Arabia.

Received: 17 March 2021 Accepted: 15 August 2021

Published online: 24 August 2021

\section{References}

1. Persico M, Iolascon A (2010) Steatosis as a co-factor in chronic liver diseases. World J Gastroenterol 16(10):1171-1176. https://doi.org/10.3748/ wjg.v16.110.1171

2. Reeder SB, Sirlin CB (2010) Quantification of liver fat with magnetic resonance imaging. Magn Reson Imaging Clin N Am 18(3):337-ix. https://doi. org/10.1016/j.mric.2010.08.013

3. Angulo P, Keach JC, Batts KP, Lindor KD (1999) Independent predictors of liver fibrosis in patients with nonalcoholic steatohepatitis. Hepatology (Baltimore, MD) 30(6):1356-1362. https://doi.org/10.1002/hep.510300604

4. Gramlich T, Kleiner DE, McCullough AJ, Matteoni CA, Boparai N, Younossi ZM (2004) Pathologic features associated with fibrosis in nonalcoholic fatty liver disease. Hum Pathol 35(2):196-199. https://doi.org/10.1016/j. humpath.2003.09.018

5. Ekstedt M, Franzén LE, Mathiesen UL, Thorelius L, Holmqvist M, Bodemar G, Kechagias S (2006) Long-term follow-up of patients with NAFLD and elevated liver enzymes. Hepatology (Baltimore, MD) 44(4):865-873. https://doi.org/10.1002/hep.21327

6. Bach N, Thung SN, Schaffner F (1992) The histological features of chronic hepatitis $C$ and autoimmune chronic hepatitis: a comparative analysis. Hepatology (Baltimore, MD) 15(4):572-577. https://doi.org/10.1002/hep. 1840150403

7. Czaja AJ, Carpenter HA (1993) Sensitivity, specificity, and predictability of biopsy interpretations in chronic hepatitis. Gastroenterology 105(6):1824-1832. https://doi.org/10.1016/0016-5085(93)91081-r

8. Lonardo A, Adinolfi LE, Loria P, Carulli N, Ruggiero G, Day CP (2004) Steatosis and hepatitis $C$ virus: mechanisms and significance for hepatic and extrahepatic disease. Gastroenterology 126(2):586-597. https://doi.org/ 10.1053/j.gastro.2003.11.020

9. Noureddin M, Wong MM, Todo T, Lu SC, Sanyal AJ, Mena EA (2018) Fatty liver in hepatitis $C$ patients post-sustained virological response with direct-acting antivirals. World J Gastroenterol 24(11):1269-1277. https:// doi.org/10.3748/wjg.v24.111.1269

10. Lok AS, Everhart JE, Chung RT, Kim HY, Everson GT, Hoefs JC, Greenson JK, Sterling RK, Lindsay KL, Lee WM, Di Bisceglie AM, Bonkovsky HL, Ghany MG, Morishima C, HALT-C Trial Group (2009) Evolution of hepatic steatosis in patients with advanced hepatitis $C$ : results from the hepatitis $C$ antiviral long-term treatment against cirrhosis (HALT-C) trial. Hepatology (Baltimore, MD) 49(6):1828-1837. https://doi.org/10.1002/hep.22865

11. Lok AS, Everhart JE, Chung RT, Padmanabhan L, Greenson JK, Shiffman ML, Everson GT, Lindsay KL, Bonkovsky HL, Di Bisceglie AM, Lee WM, Morgan TR, Ghany MG, Morishima C, HALT-C Trial Group (2007) Hepatic steatosis in hepatitis $\mathrm{C}$ : comparison of diabetic and nondiabetic patients 
in the hepatitis $\mathrm{C}$ antiviral long-term treatment against cirrhosis trial. Clin Gastroenterol Hepatol 5(2):245-254. https://doi.org/10.1016/j.cgh.2006. 11.002

12. Cheng FK, Torres DM, Harrison SA (2014) Hepatitis $C$ and lipid metabolism, hepatic steatosis, and NAFLD: still important in the era of direct acting antiviral therapy? J Viral Hepatitis 21(1):1-8. https://doi.org/10.1111/ jvh. 12172

13. Lonardo A, Adinolfi LE, Restivo L, Ballestri S, Romagnoli D, Baldelli E, Nascimbeni F, Loria P (2014) Pathogenesis and significance of hepatitis C virus steatosis: an update on survival strategy of a successful pathogen. World J Gastroenterol 20(23):7089-7103. https://doi.org/10.3748/wjg.v20. i23.7089

14. Krssák M, Hofer H, Wrba F, Meyerspeer M, Brehm A, Lohninger A, SteindlMunda P, Moser E, Ferenci P, Roden M (2010) Non-invasive assessment of hepatic fat accumulation in chronic hepatitis $\mathrm{C}$ by $1 \mathrm{H}$ magnetic resonance spectroscopy. Eur J Radiol 74(3):e60-e66. https://doi.org/10.1016/j. ejrad.2009.03.062

15. Hofer H, Bankl HC, Wrba F, Steindl-Munda P, Peck-Radosavljevic M, Osterreicher C, Mueller C, Gangl A, Ferenci P (2002) Hepatocellular fat accumulation and low serum cholesterol in patients infected with HCV-3a. Am J Gastroenterol 97(11):2880-2885. https://doi.org/10.1111/j.1572-0241. 2002.07056.x

16. Kouyoumjian SP, Chemaitelly H, Abu-Raddad L (2018) Characterizing hepatitis $\mathrm{C}$ virus epidemiology in Egypt: systematic reviews, meta-analyses, and meta-regressions. Sci Rep 8(1):1661. https://doi.org/10.1038/ s41598-017-17936-4

17. Anwar W, Sarwar M, Hussain AB, Tariq WU, Saif M (2006) Significance of occult HBV infection in patients with chronic hepatitis C. J Coll Phys SurgPak 16(3):192-195

18. Boyce CJ, Pickhardt PJ, Kim DH, Taylor AJ, Winter TC, Bruce RJ, Lindstrom MJ, Hinshaw JL (2010) Hepatic steatosis (fatty liver disease) in asymptomatic adults identified by unenhanced low-dose CT. AJR Am J Roentgenol 194(3):623-628. https://doi.org/10.2214/AJR.09.2590

19. Qayyum A, Goh JS, Kakar S, Yeh BM, Merriman RB, Coakley FV (2005) Accuracy of liver fat quantification at MR imaging: comparison of out-ofphase gradient-echo and fat-saturated fast spin-echo techniques-initial experience. Radiology 237(2):507-511. https://doi.org/10.1148/radiol. 2372040539

20. Cassidy FH, Yokoo T, Aganovic L, Hanna RF, Bydder M, Middleton MS, Hamilton G, Chavez AD, Schwimmer JB, Sirlin CB (2009) Fatty liver disease: MR imaging techniques for the detection and quantification of liver steatosis. Radiographics 29(1):231-260. https://doi.org/10.1148/rg.29107 5123

21. Ma X, Holalkere NS, Kambadakone RA, Mino-Kenudson M, Hahn PF, Sahani DV (2009) Imaging-based quantification of hepatic fat: methods and clinical applications. Radiographics 29(5):1253-1277. https://doi.org/ $10.1148 / \mathrm{rg} .295085186$

22. Longo R, Pollesello P, Ricci C, Masutti F, Kvam BJ, Bercich L, Crocè LS, Grigolato P, Paoletti S, de Bernard B (1995) Proton MR spectroscopy in quantitative in vivo determination of fat content in human liver steatosis. J Magn Reson Imaging 5(3):281-285. https://doi.org/10.1002/jmri.18800 50311

23. Kleiner DE, Brunt EM, Van Natta M, Behling C, Contos MJ, Cummings OW, Ferrell LD, Liu YC, Torbenson MS, Unalp-Arida A, Yeh M, McCullough AJ, Sanyal AJ, Nonalcoholic Steatohepatitis Clinical Research Network (2005) Design and validation of a histological scoring system for nonalcoholic fatty liver disease. Hepatology (Baltimore, MD) 41(6):1313-1321. https:// doi.org/10.1002/hep.20701

24. Bedossa P, Poitou C, Veyrie N, Bouillot JL, Basdevant A, Paradis V, Tordjman J, Clement K (2012) Histopathological algorithm and scoring system for evaluation of liver lesions in morbidly obese patients. Hepatology (Baltimore, MD) 56(5):1751-1759. https://doi.org/10.1002/hep.25889

25. Mihm S, Fayyazi A, Hartmann H, Ramadori G (1997) Analysis of histopathological manifestations of chronic hepatitis $C$ virus infection with respect to virus genotype. Hepatology (Baltimore, MD) 25(3):735-739. https://doi.org/10.1002/hep.510250340
26. Tsochatzis E, Papatheodoridis GV, Manesis EK, Chrysanthos N, Kafiri G, Petraki K, Hadziyannis E, Pandelidaki H, Zafiropoulou R, Savvas S, Koskinas J, Archimandritis AJ (2007) Hepatic steatosis in genotype 4 chronic hepatitis $C$ is mainly because of metabolic factors. Am J Gastroenterol 102(3):634-641. https://doi.org/10.1111/j.1572-0241.2006.01025.x

27. Rastogi R, Gupta S, Garg B, Vohra S, Wadhawan M, Rastogi H (2016) Comparative accuracy of CT, dual-echo MRI and MR spectroscopy for preoperative liver fat quantification in living related liver donors. Indian J Radiol Imaging 26(1):5-14. https://doi.org/10.4103/0971-3026.178281

28. Orlacchio A, Bolacchi F, Cadioli M, Bergamini A, Cozzolino V, Angelico M, Simonetti $G$ (2008) Evaluation of the severity of chronic hepatitis $C$ with 3-T1H-MR spectroscopy. AJR Am J Roentgenol 190(5):1331-1339. https:// doi.org/10.2214/AJR.07.2262

29. van Werven JR, Marsman HA, Nederveen AJ, Smits NJ, ten Kate FJ, van Gulik TM, Stoker J (2010) Assessment of hepatic steatosis in patients undergoing liver resection: comparison of US, CT, T1-weighted dualecho MR imaging, and point-resolved $1 \mathrm{H}$ MR spectroscopy. Radiology 256(1):159-168. https://doi.org/10.1148/radiol.10091790

30. Idilman IS, Keskin O, Celik A, Savas B, Elhan AH, Idilman R, Karcaaltincaba $M$ (2016) A comparison of liver fat content as determined by magnetic resonance imaging-proton density fat fraction and MRS versus liver histology in non-alcoholic fatty liver disease. Acta Radiol (Stockholm, Sweden: 1987) 57(3):271-278. https://doi.org/10.1177/0284185115 580488

31. Noureddin M, Lam J, Peterson MR, Middleton M, Hamilton G, LeTA, Bettencourt R, Changchien C, Brenner DA, Sirlin C, Loomba R (2013) Utility of magnetic resonance imaging versus histology for quantifying changes in liver fat in nonalcoholic fatty liver disease trials. Hepatology (Baltimore, MD) 58(6):1930-1940. https://doi.org/10.1002/hep.26455

32. El-Badry AM, Breitenstein S, Jochum W, Washington K, Paradis V, RubbiaBrandt L, Puhan MA, Slankamenac K, Graf R, Clavien PA (2009) Assessment of hepatic steatosis by expert pathologists: the end of a gold standard. Ann Surg 250(5):691-697. https://doi.org/10.1097/SLA.0b013e3181 bcd6dd

33. Traussnigg S, Kienbacher C, Gajdošík M, Valkovič L, Halilbasic E, Stift J, Rechling C, Hofer H, Steindl-Munda P, Ferenci P, Wrba F, Trattnig S, Krššák M, Trauner M (2017) Ultra-high-field magnetic resonance spectroscopy in non-alcoholic fatty liver disease: Novel mechanistic and diagnostic insights of energy metabolism in non-alcoholic steatohepatitis and advanced fibrosis. Liver Int 37(10):1544-1553. https://doi.org/10.1111/liv. 13451

34. Chalasani N, Wilson L, Kleiner DE, Cummings OW, Brunt EM, Unalp A, NASH Clinical Research Network (2008) Relationship of steatosis grade and zonal location to histological features of steatohepatitis in adult patients with non-alcoholic fatty liver disease. J Hepatol 48(5):829-834. https://doi.org/10.1016/j.jhep.2008.01.016

35. Sheikh MY, Choi J, Qadri I, Friedman JE, Sanyal AJ (2008) Hepatitis C virus infection: molecular pathways to metabolic syndrome. Hepatology (Baltimore, MD) 47(6):2127-2133. https://doi.org/10.1002/hep.22269

36. Patton HM, Patel K, Behling C, Bylund D, Blatt LM, Vallée $M$, Heaton $S$, Conrad A, Pockros PJ, McHutchison JG (2004) The impact of steatosis on disease progression and early and sustained treatment response in chronic hepatitis C patients. J Hepatol 40(3):484-490. https://doi.org/10. 1016/j.jhep.2003.11.004

37. Neuschwander-Tetri BA, Caldwell SH (2003) Nonalcoholic steatohepatitis: summary of an AASLD Single Topic Conference. Hepatology (Baltimore, MD) 37(5):1202-1219. https://doi.org/10.1053/jhep.2003.50193

38. Talaat A, Fatin A, Elsawy A (2012) Hepatic steatosis in HCV infection genotype 4 in Egypt. Egypt Liver J 2(1):16-21. https://doi.org/10.1097/01.ELX. 0000403334.90863 .91

39. Fishbein MH, Gardner KG, Potter CJ, Schmalbrock P, Smith MA (1997) Introduction of fast MR imaging in the assessment of hepatic steatosis. Magn Reson Imaging 15(3):287-293. https://doi.org/10.1016/s0730725x(96)00224-x

40. Wyatt J, Baker H, Prasad P, Gong YY, Millson C (2004) Steatosis and fibrosis in patients with chronic hepatitis C. J Clin Pathol 57(4):402-406. https:// doi.org/10.1136/jcp.2003.009357 
41. Leandro G, Mangia A, Hui J, Fabris P, Rubbia-Brandt L, Colloredo G, Adinolfi LE, Asselah T, Jonsson JR, Smedile A, Terrault N, Pazienza V, Giordani MT, Giostra E, Sonzogni A, Ruggiero G, Marcellin P, Powell EE, George J, Negro F, HCV Meta-Analysis (on) Individual Patients' Data Study Group (2006) Relationship between steatosis, inflammation, and fibrosis in chronic hepatitis C: a meta-analysis of individual patient data. Gastroenterology 130(6):1636-1642. https://doi.org/10.1053/j.gastro.2006.03.014

42. Anderson N, Borlak J (2008) Molecular mechanisms and therapeutic targets in steatosis and steatohepatitis. Pharmacol Rev 60(3):311-357. https://doi.org/10.1124/pr.108.00001

43. Modaresi Esfeh J, Ansari-Gilani K (2016) Steatosis and hepatitis C. Gastroenterol Rep 4(1):24-29. https://doi.org/10.1093/gastro/gov040
44. Cho SG, Kim MY, Kim HJ, Kim YS, Choi W, Shin SH, Hong KC, Kim YB, Lee $J$, Suh CH (2001) Chronic hepatitis: in vivo proton MR spectroscopic evaluation of the liver and correlation with histopathologic findings. Radiology 221(3):740-746. https://doi.org/10.1148/radiol.2213010106

\section{Publisher's Note}

Springer Nature remains neutral with regard to jurisdictional claims in published maps and institutional affiliations.

\section{Submit your manuscript to a SpringerOpen ${ }^{\circ}$ journal and benefit from:}

- Convenient online submission

- Rigorous peer review

- Open access: articles freely available online

- High visibility within the field

- Retaining the copyright to your article

Submit your next manuscript at $\mathbf{s p r i n g e r o p e n . c o m ~}$ 